\title{
The Experienced Self and Other Scale: A technique for assaying the experience of one's self in relation to the other
}

\author{
Erel Shvil \\ Columbia University \& \\ New York State \\ Psychiatric Institute
}

\author{
Herbert Krauss \\ Pace University
}

\author{
Elizabeth Midlarsky \\ Columbia University
}

The construct "self" appears in diverse forms in theories about what it is to be a person. As the sense of "self" is typically assessed through personal reports, differences in its description undoubtedly reflect significant differences in peoples' apperception of self. This report describes the development, reliability, and factorial structure of the Experience of Sense of Self (E-SOS), an inventory designed to assess one's perception of self in relation to the person's perception of various potential "others." It does so using Venn diagrams to depict and quantify the experienced overlap between the self and "others." Participant responses to the instrument were studied through Exploratory Factor Analysis. This yielded a five-factor solution: 1) Experience of Positive Sensation; 2) Experience of Challenges; 3) Experience of Temptations; 4) Experience of Higher Power; and 5) Experience of Family. The items comprising each of these were found to produce reliable subscales. Further research with the E-SOS and suggestions for its use are offered.

Keywords: self, sense of self, Venn diagram, self and other

The construct "self" appears in diverse ways in psychological and philosophical theories about what it is to be a person. To indicate a few: self is often introduced as "a fundamental part of human nature, one that is broad and essential, one that enables us to apperceive a person as distinctive in some way" (Reber \& Reber, 2001). "Self" is also used as a summary representation of the thoughts, insights, and ideas that one has about oneself. "Self" may also refer to the overall personality or organism. According to Margolis (1987), the self is associated with a person's experiencing agency, a sense of having the ability to affect the environment. The "self" may also be inferred from the apperception that one's stream of experience has a personal center of gravity (Margolis, 1987).

This report will review concepts of the "self" in psychosocial thought, putting aside attempts to locate its presence in particular Central Nervous System structures or processes, and will test a measure for deriving empirical evidence of group and individual differences in the perception of the "self."

Anyone who has an overview of the human sciences, either from a historical or contemporary vantage point, will see that that something 
referred to as "self" has an important place in attempts to understand the human situation. They will also see that no informed consensus has been achieved about how "self" might be best defined or represented or, indeed, whether it exists at all. One reason for this may be that the term "self" is but a name given to a diverse and as yet unknown set of proxy variables which may or may not be affecting a diverse set of processes. That is, to use the term is to confess ignorance of what is really going on. To a degree that is undoubtedly true. But that is unlikely to be wholly the case. Two other reasons for the lack of agreement in denoting and connoting "self" are plausible and straightforward. The first is that much of the disagreement about the self arises simply because, as is frequently the case with developing science, interested observers are viewing the proverbial elephant, in this instance the self, from different angles, through lenses of varying power while focusing upon different portions of its anatomy. If this be the case, one can reasonably assume that some resolution of the disparities among observers in viewing the self will be achieved eventually. Another interesting, plausible, alternative explanation for the divergent depictions of "self" is that each, at its core, accurately reflects individual differences among key and influential reporters. While true to their particular phenomenology of self, each generalized, and inappropriately concluded that their self fits all.

William James' (1890/1983), for example, believed that however one conceived self, it was certainly a subject of experience. He noted that the self was, if nothing else, the center of the person's psychological universe and the eye through which other aspects of the world were seen.

In Western cultures since the time of Descartes and Locke, when the self has been the object of study, it has usually been observed through three different lenses - the bodily (or material), the relational (or social), and the reflective (Seigel, 2005). Regarding a reflective self, Gordon and Gergen (1968), for example, suggest that people's self-concepts reflect their views of what others perceive them to be as well as their reactions to others' view of them. This theory of self-perception, this understanding of self-concept or of self-knowledge, questions the assumption that each individual, necessarily, possesses a unitary unchangeable self that represents unique and personal experiences and personality features (Brewer \& Chen, 2007; Turner \& Onorato, 1999; Tyler, Kramer, \& John, 1999). It hypothesizes that one's apperception of one's self is a function of the specific social context and experience of that context. From this viewpoint, instead of a single self, multiple selves, each reflecting aspects of the various social allegiances that the person has, may arise (Gordon, 1968).

A similar conclusion emerges from social psychological research. In particular, Higgins (1996) argues that self-knowledge is not primarily sought in isolation or for its own sake. He claims that, in order to 


\section{THE EXPERIENCED SELF AND OTHER SCALE}

understand the building blocks of the self, one should not ask, - "Who am I?", but, rather, -"What is my relation to the world?" In this view, selfknowledge is pursued for adaptive benefits that would improve personenvironment fit. According to Robins, Tracy, and Trzesniewski (2008) each person has various representations that consist of many identitiespersonal, relational, social, and collective. These different identities or multiple selves (Markus \& Nurius, 1986) permit the individual to differentiate self from others, giving a sense of continuity and unity over time, while also helping the person to adapt better in complex social situations (Robins, et al., 2008). According to Gergen (1972) the experience of multiple selves is a crucial aspect of our existence and it plays a significant role in psychological well-being.

Baumeister (1998), taking a somewhat different approach, argues that the core intuition that lies behind the notion of self would be lost if indeed a person had multiple selves. According to Baumeister, the essence of self involves integration of diverse experiences into a unity and "the discussion of multiplicity should be regarded as heuristics or metaphors" (p. 682). Thus, Baumeister suggests that self-knowledge begins when attention turns toward its source, a phenomenon often called "reflexive consciousness" in social psychology. Moreover, self-knowledge cannot be "observed in quiescent isolation" (p. 699) and it cannot be known directly. One can create detailed self-knowledge by observing the self in action and knowing one's thoughts and feelings (Baumeister, 1998). If Baumeister is correct in his depiction of self-creation, to understand the process would require an accurate appreciation of reflexive consciousness, namely, how consciousness comes to apperceive the information available to it about itself and how it uses that information to influence the emerging self. Viewed in this way, aside from emphasizing the necessity of self-cohesion, Baumeister's position on self construction is not incompatible with that of the social interactionists.

In sum, from the foregoing psychosocial perspectives, the self is not a simple, necessarily singular object, but rather it is a social construction. It is constructed out of interactions with others. Because of this, any mapping of the self must include in some form a description of its relations to the others involved significantly and necessarily in its formation.

Strawson (e.g. 1997, 1999), a philosopher with an interest in self who has significantly influenced cognitive studies, focuses upon phenomenal self-persistence, that is, apperceived core self-continuity over time, and argues for individual differences in the longitudinal experience of selfsameness. In so doing he opened another area of the experience of self to research. Reviewing his apperceptions of self over time, he reports, is like imagining distinct and discrete pearls held together by a string. The string holding the pearls together is Strawson's intellectual understanding that 
these pearls represent separate periods of his self-experience and that after death, he will end. Until he ends, however, more pearls may be added to the string, more independent, isolated islands of experience, each with a phenomenal self that bursts into existence only to be, in the natural course of time, extinguished and supplanted by a new self. Strawson knows that others have reported different phenomenologies of self experience. These differences in apperceptions of self-persistence, and thus self, he attributes largely to unspecified genotypic diversity (1999).

An entirely different vision of the self is presented by Jung (e.g. 1959/1969, 1971, McGuire \& Hull, 1977). To Jung the self is the whole personality, not just the parts of it which a person is, or can become, conscious. Consonant with his understanding of the human condition, Jung sees each person as individuated out of an evolutionary collective history to which he or she remains intrinsically linked. This is a view not much different from that of Popper and Eccles (e.g. 1977) and Eccles (e.g. 1980, 1989/1991), although, as would be expected, Popper and Eccles certainly stress cultural interaction more than Jung does and certainly have a different attitude toward materialism than he does.

Given the diverse conceptualizations of self and its topography, and empirical science's current inability to physically locate its habitus, one might reasonably conclude that it is a term best discarded. However, given the notion's popularity and its importance to psychology and other human sciences, this is unlikely to happen. Instead of continuing to propose nomothetic selves and then searching for signs that they exist and are embodied, an alternative, more heuristically useful and potentially productive research strategy suggests itself: First assay how people apperceive their self. Second study the sense of self that individuals have. Fundamental to that proposed investigative program or, in fact, any denotational enterprise, is the need to determine what the thing you are interested in is and what it is not. A plausible starting point for learning how one might accomplish this is the research literature pertinent to the sense of self's ontogeny.

\section{The Emergence of Self}

For Strawson (1997, 1999), an essential characteristic of human life occurs when one realizes that one's thoughts or mental representations are unobservable by others. Strawson (1997) calls this "the sense of the mental self." It is a normal process that, he believes, is usually formed and first experienced during and throughout the childhood stages of development. The sense of the mental self as defined by Strawson is viewed by Laing as a "sense of autonomy." According to Laing (1965), the capacity to experience oneself as autonomous means that one has come to realize that he or she is unique from others. 


\section{THE EXPERIENCED SELF AND OTHER SCALE}

If the individual does not feel autonomous, neither his separateness from nor relatedness to others can be experienced. To lack a sense of autonomy implies that one is bound up in the other, or the other is bound up in oneself.

Developmental self-theory posits that healthy personality development requires successfully navigating a set of stages of self-development (Jensen, Huber, Cundick, \& Carlson, 1991). At birth and during the first year, no awareness of self exists (Kagan, 1998). This is because, Loevinger (1976) suggests, neonates have not yet learned to differentiate themselves from others. Sometime after the first year of life, her narrative continues, infants experience having a mind-of-their-own, and this discovery leads them to another-that other people have minds as well (Lachmann, 2004). This developmental achievement, whose origin Stern (1985) places between 9 and 15 months, Stern refers to as attaining a sense of an "intersubjective-self." Thereafter, an appropriately developing child gains ever greater facility in differentiating self from other. Taken together, the attainment of these developmental milestones set the stage for the emergence of the sense of self. The sense-of-self, according to Stern (1985), is "the primary subjective experience that organizes social experience" (p. 11).

What does it mean to say one has a "sense" of self? James (1890/1983) pointed out that the self has what appears to be a unique capacity that he termed "reflexivity": the capacity of the self to turn around and take itself as the object of its own view. Thus, the self has both a "process" aspect (the self as the knower of things) and a "content" aspect (the self as that which is known) (Mead, 1934). Hence, to James and to those who follow in his footsteps (e.g., Mead), there is a duality in the way humans experience the world. For instance, one might say, "I experience something external to me or internal to me (my body), and simultaneously, I experience myself experiencing it. My sense of self is what tells me that it is I who is experiencing what I am experiencing." Zahavi (2005) asserts that "There is a minimal sense-of-self present whenever there is self-awareness" (p. 146). And, according to Zahavi (2005), pre-reflective self-awareness and a minimal sense-of-self are integral parts of our experiential life.

In sum, it is fair to say that the "self" holds a central place in theories designed to assess the human condition. It is also fair to conclude that there is considerable disagreement about its habitus and scope of operation. In fact, there is some disagreement about whether such an entity indeed exists and, if it does, whether it persists over time, and whether it takes the same shape, or has the same characteristics in those whose possess it.

In spite of these disagreements, a consensus about the self has emerged. It is generally agreed that (1) the construct of "self" in its multiple forms has proven heuristically valuable; (2) while it is unlikely 
that the self, itself, whether it be an entity or process, is accessible to direct measurement, one's apperception of one's self is; (3) a meaningful relationship is hypothesized to exist between one's sense of self and one's self; (4) mapping one's sense of self will shed some light on one's self and its operations. Furthermore, (5) to assay one's sense of self meaningfully one must assess it in relation to one's apperception of its relationship to the other or others.

\section{Experienced Self and Other Scale (E-SOS)}

The Experienced Self and Other Scale (E-SOS) is a self-report inventory that asks how one experiences oneself in relation to potential others that are specified in the scale. Since the individual's experience of self is subjective, it was decided that the most direct and accurate way to estimate it would be through self-reports, recognizing, of course, such a procedure is not immune from the distortions that plague measurement using that technique (e.g., social desirability).

The E-SOS's items list a variety of potential "others". These include putatively significant persons (e.g., mother and father), emotions (e.g., sadness, terror), inanimate objects (e.g., internet, money, alcohol), executive functions of the personality (e.g., self-control), sacred concerns (e.g., God), cultural forms (e.g., norms), personal characteristics (intelligence, creativity), and so on. We consider these categories to be neither comprehensive nor mutually exclusive. Rather it was hoped that the items included in the scale represented "objects" diverse enough to enable a preliminary analysis of the structure of self-other relations. The goals of this analysis are to determine both whether individuals differ in the extent to which they perceive, for instance, their cell phones as part of their selves, as well as whether respondents, in general, consider their parents in the same class of objects in relationship to themselves as, for instance, money. We designed the E-SOS as a means of testing an investigative strategy. We consider it a work in progress, subject to revision, refinement, and modification for special purposes. For example, versions of the scale containing other items might be specifically designed to assess the relationship between therapist and client during treatment, or between the client and significant others in the client's life.

For each item of the E-SOS, participants rate the extent to which they experience the item as part of their sense of self by referring to a series of four two-dimensional Venn diagrams (Edwards, 2004) ranging in overlap from total to none.

According to Aron, Aron \& Smollan (1992), Pipp, Shaver, Jennings, Lamborn, and Fischer (1985) were the first to use Venn diagrams to measure closeness. In their study, they had adolescents draw two circles, one representing their self and the other their parents. Participants were 


\section{THE EXPERIENCED SELF AND OTHER SCALE}

instructed to place the circles in positions which they believed best illustrated their closeness to their parents. Influenced by this work and drawing on the content of Levinger and Snoek's scale of interpersonal attraction (1972), Aron, et al. (1992) created the Inclusion of Other in the Self Scale (IOS). The IOS has seven items. Respondents use Venn diagrams with two circles of equal size, representing the self and the other. The IOS scale seeks to measure general closeness, and has been used primarily to describe such dyadic relationships as romantic and friend relationships (Aron \& Aron, 1986; Aron, Aron, Tudor, \& Nelson, 1991; Agnew, Van Lange, Rusbult, \& Langston, 1998; Lin \& Rusbult, 1995). Subsequently, Li (2001) has used a slightly modified version of the IOS to study cultural differences in individualism and collectivism. More recently, De Cremer and Stouten (2003), using the IOS, determined that self-other merging and trust were directly related to cooperative behavior.

\section{The Development of the E-SOS}

There have been previous versions of the E-SOS (Shvil, Krauss, Midlarsky, \& Ward 2007; Shvil, Midlarsky, \& Krauss 2009). In contrast to the version of the E-SOS tested in this report, an earlier study (Shvil, et al., 2007) attempted to simultaneously measure two dimensions of relationships that one could experiences in relation to another-(1) enmeshment/overlap and (2) potency/weakness.

This previous version of the scale (Shvil, et al., 2007; Shvil, et al., 2009) contained 31 items that, on their face, fell into three categories: a) people in different degrees of familial and associational relationship to the self (e.g. family members, friends, acquaintances/neighbors), b) inanimate objects (e.g. childhood pictures, alcohol, cell phones), and c) positive/negative emotions (e.g. anxiety, depression, optimism). These items were studied by exploratory factor analysis (EFA) using principal axis factoring with oblique rotation (Allison, Gorman, \& Primavera, 1993; Floyd \& Widaman, 1995; Johnson, 1998; Streiner, 1994). The analysis of the enmeshment/overlap dimension yielded five factors with a scree plot of eigenvalues $(3.41,2.28,1.52,1.09,0.74)$ accounting for $51.65 \%$ of the variance. Eight items were removed because of either low communality estimates or dual factor loadings, leaving 23 items for the enmeshment/overlap dimension. By utilizing promax rotation with Kaiser normalization for interpretation, evidence was found for five independent factors with relatively low intercorrelations. The first factor, "Negative Emotion" $(\alpha=.79)$, comprised six items: sadness, stress, what I despise about myself, anxiety, worst fear, and hopelessness. The second factor, "View of Self," $(\alpha=.74)$, included seven items: optimism, who I want to be, positive emotion, self-control, sexuality, image/physical body, and fantasies. The third, "Persons" ( $\alpha=.71)$, had three items: acquaintances/ 
neighbors, class friend, and those over whom I have power. The fourth factor, "Objects/Substances" $(\alpha=.69)$, has a total of three items: nonprescribed drugs, prescribed drugs, and alcohol. The fifth factor, "Family" $(\alpha=.62)$, included three items: mother, father, and sibling.

The current study's aim was to substantially improve the previous version of the E-SOS (Shvil, et al., 2007). First, in order to expand the depth of the content areas already represented, items were added. The current version of the E-SOS has 45 items. Secondly, those additional items included a set whose content was metaphysical (e.g., God, fate). Third, no attempt was made to assess the potency dimension, because analysis of that dimension had proved difficult to interpret in the previous version. The current version, therefore, included all 23 items from the previous version and 22 new items, a total of 45 items (see Appendix). Since the content of the scale remained relatively unchanged, it was assumed that the current study would yield a factor structure similar to that obtained previously. Specifically, it was predicted that the current ESOS version would load on four to five clear factors, quite similar to those found previously, with the possible addition of a factor with metaphysical content. These factors would, it was hypothesized, account for similar proportions of variance as in the previous investigation.

\section{Method}

\section{Participants}

A total of 397 men and women completed the E-SOS. Their mean age was 31.1 $(\mathrm{SD}=11.37)$. Males were 21.5 percent $(N=81)$ of those sampled. Caucasians composed 70.0 percent of the sample; 7.8 percent were Asian, 7.6 percent Hispanic; 4.0 percent African-American; 0.3 per cent NativeAmerican; and 10.3 percent were in none of the preceding categories. Thirty-four per cent of those sampled indicated that they were married; 10.6 per cent that they were in a domestic partnership; 3.8 per cent that they were divorced; 0.5 per cent that they were widowed; and 51.1 percent that they were single.

\section{Procedure}

The research protocol was approved by the Institutional Review Boards of Columbia and Pace Universities; surveys were posted on-line; participant consent was obtained prior to completion of questionnaires. Participants were recruited using advertisements on websites, flyers posted at diverse locations (colleges and universities, shopping malls, supermarkets, bus terminals and subways), and TV and news media ads. 


\section{THE EXPERIENCED SELF AND OTHER SCALE}

\section{Materials}

In the current study, each of the 45 items of the E-SOS (see Appendix) asks participants to select one of four Venn diagrams. These diagrams consist of two circles of the same size. One circle represents the self and the second represents the other. In the first depiction of the two, the circles are close to one another, but not touching. From the second to the fourth, they overlap, the degree of overlap progressing in a linear fashion until, in the fourth, the circles representing self and other are completely enmeshed, represented by a single circle. By selecting the Venn diagram that represents their experience of self in relation to the targeted other, participants rate each item on a scale of 1 to 4 (See Appendix).

Before responding, participants were offered clear explanations of the symbolic meaning of the circles. For example, when the two circles are completely separate, the self is completely independent of, or separate from, the other. When the two circles completely overlap to create one circle, it indicates that no separation exists between oneself and the other. That is, the two are experienced as if the two are one. Participants were asked, in responding, to reflect upon and indicate their felt sense of overlap with the represented other at the present moment.

\section{Data Analysis}

The factorial structure of the E-SOS was evaluated by means of exploratory factor analysis (EFA) principal axis factoring, with oblique rotation to allow for correlations among the factors (Allison, Gorman, \& Primavera, 1993; Floyd \& Widaman, 1995; Johnson, 1998; Streiner, 1994). Additionally, correlational analysis was used to examine inter-factor relationships; Cronbach's alpha described the internal consistency of the subscales formed by those items which loaded most heavily on the factors extracted.

\section{Results}

\section{Exploratory Factor Analysis}

An Exploratory Factor Analysis (EFA) $(\mathrm{N}=397)$ of the 45-item E-SOS was computed using principal axis factoring with oblique rotation. It yielded eight factors with eigenvalues greater than 1.0, accounting for 60 per cent of the variance. An examination of the scree plot indicated a substantial drop in subsequent eigenvalues after five factors had been extracted, thereby suggesting that a five factor solution was more appropriate than one of eight. Such a decision is consonant with the advice 
Table 1

Rotated Factor Solution for the Experienced Self and Other Scales

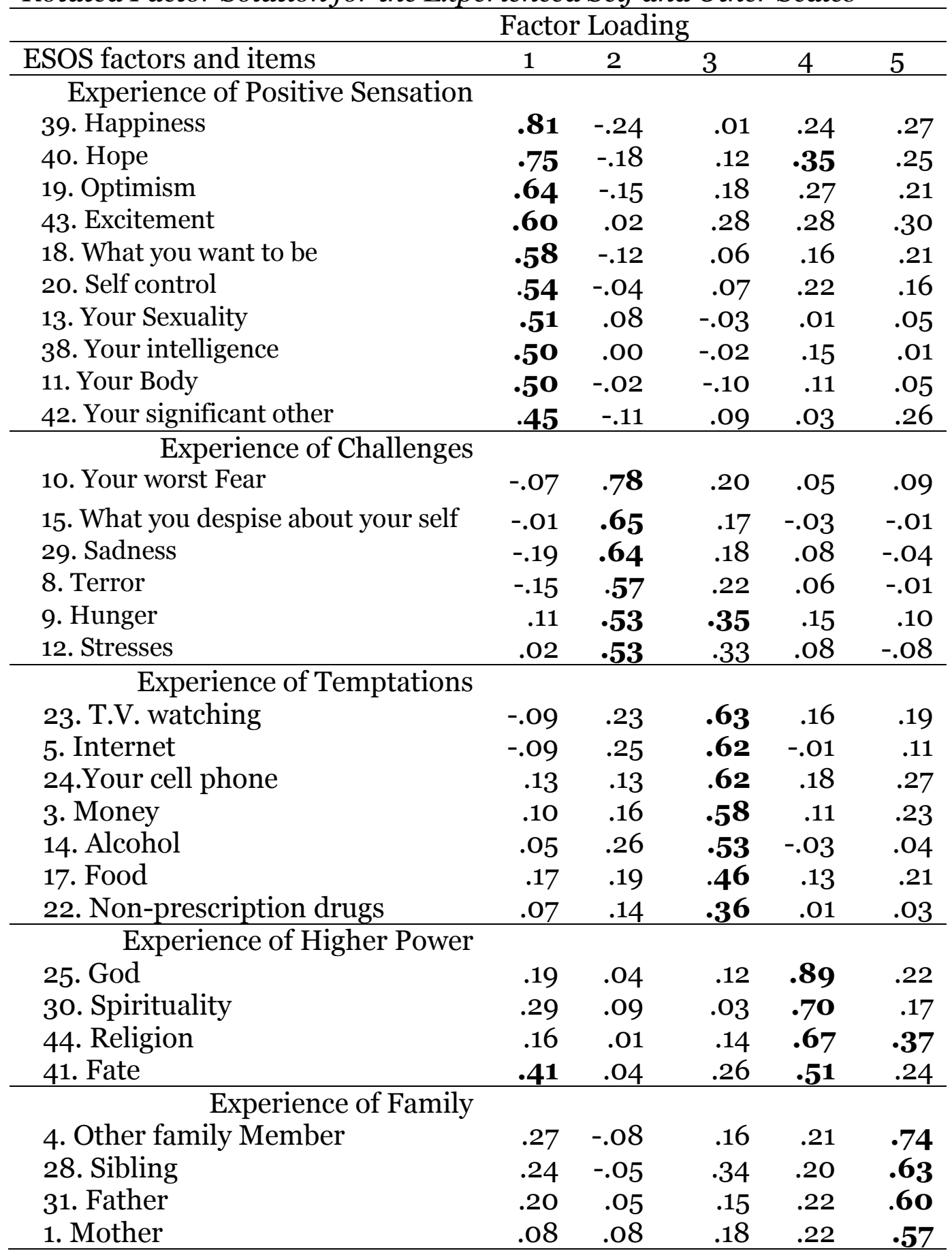

Note. $N=397$. Factor loadings $>.35$ are in boldface. Extraction Method: Principal Axis Factoring. Rotation Method: Promax with Kaiser Normalization. 
of Floyd and Widaman (1995) who argue that use of all factors having eigenvalues greater than 1.0 often results in overestimation of the number of factors that ought to be retained. Instead, they posit that the scree plot provides a more useful guide for interpreting the data. A second factor analysis was computed, specifying a five factor solution; again, principal axis factoring with oblique rotation was used.

For the final EFA, 14 candidate items were removed based on low communality estimates or dual factor loadings, leaving a total of 31 items (4 items loaded on more than one factor). An EFA of the 31 items accounted for a total of $49 \%$ of the variance (Table 1 ).

Four of the E-SOS items had significant loadings on two factors. These items were kept both because they were among the highest loading items, and because, as Costello and Osborne (2005) note, factors with three or fewer items are unlikely to be stable. The analyses in this paper follow the best practices for exploratory factor analysis (EFA, correlated solution, sufficient sample size, deletion of items with low factor loadings).

Based on a consideration of their item content, the five extracted factors were labeled 1) Experience of Positive Sensation; 2) Experience of Challenges; 3) Experience of Temptations; 4) Experience of Higher Power; and 5) Experience of Family (see Table 1).

\section{Reliability}

Cronbach's alpha for the five subscales derived from the items loading highest on each factor suggested by the EFA ranged from .65 for the Experience of Family scale to .81 for the Experience of Positive Sensation scale (Table 2).

Table 2

Intercorrelations, means, standard deviations, and reliability coefficients for the E-SOS Subscales $(N=397)$

\begin{tabular}{|c|c|c|c|c|c|c|}
\hline & Experience of & 1 & 2 & 3 & 4 & 5 \\
\hline 1. & Positive Sensation & 1.00 & & & & \\
\hline 2. & Challenges & -.02 & 1.00 & & & \\
\hline 3. & Temptations & .10 & $.37^{* *}$ & 1.00 & & \\
\hline 4. & Higher Power & $.21^{* *}$ & $.19^{* *}$ & $.20^{* *}$ & 1.00 & \\
\hline 5. & Family & $.22^{* *}$ & $.21^{* *}$ & $.30^{* *}$ & $.33^{* *}$ & 1.00 \\
\hline & Mean & 2.87 & 2.15 & 2.00 & 2.22 & 2.26 \\
\hline & $\mathrm{SD}$ & 0.53 & 0.63 & 0.53 & 0.78 & 0.62 \\
\hline & Cronbach's $\alpha$ & .81 & .77 & .73 & .78 & .65 \\
\hline
\end{tabular}




\section{Indications of Possible Subgroup Differences}

For three of the subscales, overall mean scores differences among ethnic groups were found (see Table 3): Experience of Challenges $(F(3$, $178)=3.22, p<.05)$, Temptations $(F(3,182)=4.58, p<.05)$, and Higher Power $(F(3,183)=3.63, p<.05)$. Post hoc analyses (Least Significant Difference) subsequently revealed that the selves of both Asian Americans and Caucasians were significantly $(p<.05)$ less enmeshed with (e.g., more differentiated from) their Experiences of Challenges and their Experience of Temptations than Latinos. Lastly, both Latinos and African Americans reported $(p<.05)$ that a Higher Power was more a part of their selves than did Caucasians.

Table 3

E-SOS factor scores by ethnicity

\begin{tabular}{lllll}
\hline & $\begin{array}{l}\text { White } \\
(\mathrm{n}=151)\end{array}$ & $\begin{array}{l}\text { Hispanic } \\
(\mathrm{n}=18)\end{array}$ & $\begin{array}{l}\text { African } \\
\text { American } \\
(\mathrm{n}=11)\end{array}$ & $\begin{array}{l}\text { Asian } \\
\text { American } \\
(\mathrm{n}=12)\end{array}$ \\
\cline { 2 - 5 } Subscale & $M(S D)$ & $M(S D)$ & $M(S D)$ & $M(S D)$ \\
\hline $\begin{array}{l}\text { Positive } \\
\text { Sensation }\end{array}$ & $2.96(.53)$ & $3.04(.52)$ & $2.92(.59)$ & $2.76(.54)$ \\
Challenges & $2.15(.60)$ & $2.55(.81)$ & $2.34(.75)$ & $1.88(.59)$ \\
Temptations & $1.90(.52)$ & $2.33(.73)$ & $2.09(.72)$ & $1.64(.46)$ \\
Higher Power & $2.17(.74)$ & $2.61(.56)$ & $2.72(.96)$ & $2.39(.70)$ \\
Family & $2.25(.62)$ & $2.44(.59)$ & $2.31(.45)$ & $2.22(.88)$ \\
\hline
\end{tabular}

\section{Discussion}

The aim of this investigation was to produce an empirically derived tool by means of which the putative self's relationship to its psycho-sociophysical milieu might be addressed and assessed. With that goal in mind, a self-report inventory that asked respondents to indicate, using twodimensional Venn diagrams, the extent to which they experienced self as differentiated from potential "others" was developed. The "others" studied ranged from family members (e.g., mother) to positive emotions (e.g., happiness), negative emotions (e.g., terror), metaphysical constructs (e.g., spirituality), one's self of the future, personal attributes (e.g., self-control), socially useful objects (e.g., money), and physical attributes (e.g., your body). To be sure, as soon as these potential "others" are listed, other possibilities, drawn from many categories immediately come to minde.g., "war," "love," and so on, demonstrating how complex and fecund further explorations might be. In all, 45 items, based upon previous research findings (Shvil, et al., 2007) were selected for the proposed 


\section{THE EXPERIENCED SELF AND OTHER SCALE}

inventory. Necessarily, many objects or categories may not have been represented thereby leaving a more complete mapping of self in relation to other to further research.

Before describing the results of this study and suggesting further research, a few words need be offered in defense of using a self-report technique in preference to another, and in defense of focusing upon the experienced self in relation to the other. The rationales for doing so are grounded in the historical, philosophical and empirical background of the self's study. As Whitehead (1933/1961) has pointed out, "When Descartes, Locke, and Hume undertake the analysis of experience, they utilize those elements of their own experience which be clear and distinct, fit for the exactitude of intellectual discourse." (p. 175)

That trend, to employ privileged accounts of the apperceived self when investigating that putative entity or nexus of action or experience has continued through James (1890/1993) into the current era (e.g., Baumeister, 1983; Brown, 1991; Strawson, 1999). What would constitute a more direct alternative road to the self is, in fact, not clear, in spite of the obvious challenges to veridicality-dissembling for reasons of social desirability, lack of introspective focus, and so on-that inhere in phenomenology. The technique, for all of its manifest defects, has certainly proved fruitful. And, its very application raises questions whose answers this study, and the research program of which it is a part, seek to contribute to, namely: Does the experienced self vary in key elements from person to person, and, if so, what are those elements?

As indicated in the Introduction, once the experienced self is the chosen topic of investigation, mapping it in its relation to the not-self is immediately and logically suggested. After all, the definition of anything, whether it be an entity or pure abstraction, must mark off what it is as well as what it is not. This would be true if, in the present instance, the investigator of the self is an empirically directed developmental psychologist or a psychoanalyst whose orientation is object-relations theory; whether the researcher views the self as an object or as a dynamic frame of reference, i.e. "an artificial stasis in the reality of incessant change [which] is at the heart of an understanding of mental structures" (Brown, 1991, p. 32); whether an apperceived object exists outside of mind and independent of it or "is an exteriorized concept, a mental solid growing out of change by virtue of immediate concepts. Like a size or shape constancy, change is burned within the conceptual phase of object development" (Brown, 1991, pp. 32-33)

Exploratory Factor Analysis of the E-SOS inventory, a set of 45 items designed to explore the relation of the experienced self to the experienced other, yielded a clear and reliable 31 item, 5 factor solution whose structure possessed strong psychometric properties. Four items loaded on two factors. An examination of the content of the items with high loadings 
suggested the factors be named (1) Experience of Positive Sensation, (2) Challenges, (3) Temptations, (4) Higher Power, and (5) Family. Experience of Positive Sensation was comprised of 11 items whose loadings ranged from 0.81 for "happiness" to .41 for "fate." When combined in a subscale, their reliability was quite high (Cronbach's $\alpha=$ o.81). The items demarking Experience of Challenges, 6 in number, had loadings running from 0.78 ("your worst fear") to 0.53 ("stresses") and, when combined, also produced a quite reliable subscale (Cronbach's $\alpha=$ o.77). Eight items characterized the Experience of Temptations subscale. Their factor loadings ranged from 0.63 ("T.V. watching") to 0.35 ("hunger"). The subscale they comprised was also reliable (Cronbach's $\alpha=$ 0.73). The Experience of Higher Power had five items with loadings ranging from 0.89 ("God") to 0.35 ("hope"); the Family subscale also had five items ("other family members", 0.74 , to "mother", 0.57 , and "religion", 0.37 ). Their subscale reliabilities were 0.78 and 0.65 , respectively.

As the factor structure found in this investigation corresponded to that of a study done previously (Shvil, Krauss, Midlarsky \& Ward, 2007) in which a somewhat different format was employed and a different sample surveyed, one may assume that should the current study be replicated a similar factor structure will likely be reproduced. That is not to suggest that if the E-SOS's item pool be comprehensively expanded so that it taps domains not currently represented, or, if the E-SOS be given to a different population (non-Western, for example), that the same factor structure will be present. Whether a similar or different structure is found is a research question currently under investigation.

It does seems reasonable to conclude, however, that at least five dimensions underlie reports of the experienced sense of self in relation to the experienced other, and that a scale to measure these reliably is in hand.

One of the uses to which this scale might be put is the measurement of both intra- and inter-group differences. For example, as an exercise, differences in respondent subscale scores by gender and ethnic identification were analyzed. While no significant $(\mathrm{p}<.05)$ gender effects were uncovered, ethnic differences were. Sample size (too many Caucasians, too few in other categories) make the results of the latter analysis questionable at best. Tenuous they may be, but they are indeed suggestive of the E-SOS's potential utility.

As do many investigations, this one raises a number of questions that go well beyond that of the psychometric properties of the E-SOS and its subscales. In addition to those related to inter-group, cultural differences are those that pertain to its use in mapping other individual difference $s$ and grounding them in regard to important indices of individual differences that benchmark personality dimensions such as the big five factors of personality (e.g., Costa \& McCrae, 1992), attachment style (e.g., 


\section{THE EXPERIENCED SELF AND OTHER SCALE}

Griffin \& Bartholomew, 1994), mindfulness (e.g., Conte et al., 1990). Similarly, for those interested in psychopathology or object-relations theory, determining the relationship between the E-SOS's total score, representing their general style of enmeshment or their subscale scores, say, Challenges, and markers of abnormal behavior may well be of interest. Of import, to cite another example, is the possibility that a person's improvement in psychotherapy could be tracked as a function of the measured increased or decreased differentiation of the self and other. Another set of queries of interest to health practitioners might be the extent to which a person's experienced self is enmeshed with treatment such as dialysis and whether or not that predicts treatment adherence. To do this might require additional items pertinent to the treatment under investigation to be added to the E-SOS: for example, items such as "dialysis machine," "dialysis technician," "dialysis center," "nephrologist" and so forth. Also to be determined is whether the E-SOS need be supplemented with additional scales which locate self and other in semantic space, that is, assigning potency, activity and evaluation to the rating of each self-other dyad, before accurate prediction of other variables will become possible. For, it may prove important for some uses to not only know, for instance, that mother and self are totally enmeshed, but how powerful, how good, how active each is experienced as being. Clearly, much remains to be done, but it appears a first step has been taken.

Author Notes: Correspondence concerning this article should be addressed to Erel Shvil, Department of Psychiatry, Columbia University. Tel: (646)-774-8013; E-mail: es2297@columbia.edu

\section{References}

Agnew, C. R., Van Lange P. A. M., Rusbult, C. E., \& Langston, C. A. (1998). Cognitive interdependence: Commitment and the mental representation of close relationships. Journal of Personality and Social Psychology, 74, 939954.

Allison, D. B, Gorman, B. S, \& Primavera, L. H. (1993). Some of the most common questions asked of statistical consultants: Our favorite responses and recommended readings. Genetic, Social, and General Psychology Monographs, 119, 153-185.

Aron, A., \& Aron, E. N. (1986). Love as the expansion of self: Understanding attraction and satisfaction. New York: Hemisphere.

Aron, A., Aron, E. N., \& Smollan, D. (1992). Inclusion of other in the self scale and the structure of interpersonal closeness. Journal of Personality and Social Psychology, 63, 596-612. 


\section{SHVIL, KRAUSS, MIDLARSKY}

Aron, A., Aron, E. N., Tudor, M., \& Nelson, G. (1991). Close relationships as including other in the self. Journal of Personality and Social Psychology. $60,241-253$.

Baumeister, R. F. (1998). The self. In D. T. Gilbert, S. T. Fiske, \& G. Lindzey (Eds.), Handbook of social psychology (pp. 680- 740). Boston: McGrawHill.

Brewer, M. B., \& Chen, Y. (2007). Where (Who) are collectives in collectivism? Toward conceptual clarification of individualism and collectivism. Psychological Review, 114, 133-151.

Brown, J. W. (1991). Self and process: Brain states and the conscious present. New York: Springer-Verlag.

Conte, H. R, Plutchik, R, Jung, B. B., Picard, S., Karasu, T. B., \& Lotterman, A. (1990). Psychological mindedness as a predictor of psychotherapy outcome: A preliminary report. Comprehensive Psychiatry, 31, 426-431.

Costa, P. T. \& McCrae, R. R. (1992). Professional manual: Revised NEO personality inventory (NEO-PI-R) and NEO five-factor inventory (NEOFFI). Odessa, FL: Psychological Assessment Resources.

Costello, A. B. \& Osborne, J. W. (2005). Best practices in exploratory factor analysis: four recommendations for getting the most from your analysis. Practical Assessment Research \& Evaluation, 10. Available online: http://pareonline.net/getvn.asp?v=10\&n=7

De Cremer, D., \& Stouten, J. (2003). When do people find cooperation most justified? The effect of trust and self-other merging in social dilemmas. Social Justice Research, 16, 41-52.

Eccles, J. C. (1980). The human psyche. New York: Springer.

Eccles, J. C. (1989/1991). Evolution of the brain: Creation of the self. London: Routledge.

Edwards, A. W. F. (2004). Cogwheels of the mind; The story of Venn diagrams. Baltimore: The Johns Hopkins University Press.

Floyd, F. J., \& Widaman, K. F. (1995). Factor analysis in the development and refinement of clinical assessment instruments. Psychological Assessment. 7, 286-299.

Gergen, K. J. (1972). Multiple identities: The healthy, happy human being ears many masks. Psychology Today, 5, 31-35.

Gordon, C. (1968). Self-conceptions: Configurations of content. In C. Gordon \& K. J. Gergen (Eds.), The self in social interaction (pp.115-136). New York: Wiley.

Gordon, C., \& Gergen, K. J. (1968). The self in social interaction. New York: Wiley.

Griffin, D. W., \& Bartholomew, K. (1994). Models of the self and other: Fundamental dimensions underlying measures of adult attachment. Journal of Personality and Social Psychology, 67, 430-445.

Higgins, E. T. (1996). The "self- digest:" Self- knowledge serving self- regulatory functions. Journal of Personality and Social Psychology, 71, 1062-1083.

James, W. (1890/1983). The principles of psychology. Cambridge, MA: Harvard University Press. 


\section{THE EXPERIENCED SELF AND OTHER SCALE}

Jensen, L., Huber, C., Cundick, B., \& Carlson, J. (1991). Development of a selftheory and measurement scale. Journal of Personality Assessment, 57, 521530.

Johnson, D. E. (1998). Applied multivariate methods for data analysts. Duxbury, Belmont, CA.

Jung, C. G. (1959/1969). The archetypes and the collective unconscious. Princeton, NJ: Princeton University Press.

Jung, C. G. (1971). The portable Jung. New York: Viking.

Kagan, J. (1998). Is there a self in infancy? In M. Ferrari \& R. J. Sternberg (Eds.). Self awareness: Its nature and development (pp. 137-147). New York: Guilford Press.

Lachmann, F. M. (2004). Identity and self. International Forum of Psychoanalysis. 13, 246- 253.

Laing, R. D. (1965). The divided self: An existential study in sanity and madness. Middlesex, England: Penguin Books.

Levinger, G., \& Snoek, J. D. (1972). Attraction in relationship: A new look at interpersonal attraction. Morristown, NJ: General Learning Press.

Li, H. Z. (2001). Intrusive and co-operative interruptions in inter- and intracultural dyadic discourse. Journal of Language and Social Psychology, 20, 259-284.

Lin, Y. H. W., \& Rusbult, C. E. (1995). Commitment to dating relationships and cross-sex friendships in America and China: The impact of centrality of relationship, normative support, and investment model variables. Journal of Social and Personal Relationships, 12, 7-26.

Loevinger, J. (1976). Ego development: Concepts and theories. San Francisco: Jossey-Bass.

Margolis, J. (1987). Eliminating selves in the psychological sciences. In P. YoungEisendrath, \& J. A. Hall, (Eds.), The book of the self: Person, pretext and process (pp.42-67). New York: New York University Press.

Markus, H., \& Nurius, P. (1986). Possible selves. American Psychology, 41, 954969.

McGuire, W. \& Hull, R. F. C. (Eds.) (1977). C. G. Jung speaking: Interviews and encounters. Princeton, NJ: Princeton University Press.

Mead, G. H. (1934). Mind, self, and society. Chicago: University of Chicago Press.

Pipp, S., Shaver, P., Jennings, L., Lamborn, S., \& Fischer, K. W. (1985). Adolescents' theories about the development of their relationships with parents. Journal of Personality and Social Psychology, 48(4), 991-1001.

Popper, K. R., \& Eccles, J. C. (1977). The self and its brain. New York: SpringerVerlag.

Reber, A. S., \& Reber, E. (2001). The Penguin dictionary of psychology ( $3^{\text {rd }}$ ed.). London: Penguin.

Robins, R. W. Tracy, J. L., \& Trzesniewski, K. H. (2008). Naturalizing the self. In O. P. John, R. W. Robins, \& L. A. Pervin (Eds.). Handbook of personality: Theory and research (3rd ed.), (pp.421-447). The Guilford Press.

Seigel, J. (2005). The idea of the self: Thought and experience in Western Europe since the seventeenth century. Cambridge: University Press.

Shvil, E., Krauss, H., H., Midlarsky, E., \& Ward, A. W. (May 2007). Self and other scale: A technique for assaying one's sense of self. Poster presented the 


\section{SHVIL, KRAUSS, MIDLARSKY}

19th Annual Convention of the Association for Psychological Science, Washington, DC.

Shvil, E., Midlarsky, E., \& Krauss, H. H. (August 2009). Self and other scale: A technique for assaying one's experience of self in relation to other. Poster presented at the 117th Annual Convention of the American psychological Association, Toronto, Canada.

Stern, D. (1985). The interpersonal world of the infant. New York: Basic.

Strawson, G. (1997). The self. Journal of Consciousness Studies, 4, 405-428.

Strawson, G. (1999). The sense of the self. In Carbble, M. \& James, C. (Eds.), From soul to self: Post-colonial theory, India and the mystic east (pp. 126154). London: Routledge.

Streiner, D. L. (1994). Figuring out factors: The use and misuse of factor analysis. Canadian Journal of Psychiatry. 39, 135-140.

Turner, J. C., \& Onorato, R. S. (1999). Social identity, personality, and the selfconcept: Self categorization perspective. In T. R. Tyler, R. M. Kramer, \& O. P. John (Eds.). The psychology of the social self (pp. 11-46). Mahwah, NJ: Erlbaum.

Tyler, T. R., Kramer, R. M., \& John, O. P. (Eds.). (1999). The Psychology of the Social Self. Mahwah, NJ: Erlbaum.

Whitehead, A. N. (1933/1961). Adventures of ideas. New York: Free Press.

Zahavi, D. (2005). Subjectivity and selfhood: Investigating the first-person perspective. Cambridge, MA: The MIT Press. 


\section{Appendix}

\section{E-SOS}

Below there are four pairs of circles. Each pair represents a kind of relationship between yourself and other things in the world, which may be or not be part of yourself. You are asked to choose the number that best represents the relationship between yourself and the other things. For Example:

1. When two of the circles are not touching each other at all (diagram 1) it means that you are completely independent or separated from the other thing (e.g. mother, father etc.).

2. When two of the circles completely overlap and create one circle (diagram 4), it means that there is no separation between yourself and the other thing, as if both of you are one.

\section{Please keep in mind that your answers should reflect your present state.}

1<smiles>C1CCCCCC1</smiles>

self<smiles>C1CCCCC1</smiles>

$\mathrm{X}$
2

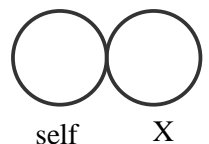

3

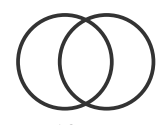

self $\mathrm{X}$
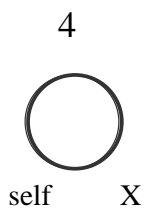

Completely independent

\section{Relationship between your self and...}

\begin{tabular}{|l|l|llll|}
\hline 1 & Mother & 1 & 2 & 3 & 4 \\
\hline 2 & Childhood dreams & 1 & 2 & 3 & 4 \\
\hline 3 & Money & 1 & 2 & 3 & 4 \\
\hline 4 & Other family members & 1 & 2 & 3 & 4 \\
\hline 5 & Internet & 1 & 2 & 3 & 4 \\
\hline 6 & Acquaintances & 1 & 2 & 3 & 4 \\
\hline 7 & Admired figure & 1 & 2 & 3 & 4 \\
\hline 8 & Terror & 1 & 2 & 3 & 4 \\
\hline 9 & Hunger & 1 & 2 & 3 & 4 \\
\hline 10 & Your worst fear & 1 & 2 & 3 & 4 \\
\hline 11 & Your body & 1 & 2 & 3 & 4 \\
\hline 12 & Stresses & 1 & 2 & 3 & 4 \\
\hline 13 & Your sexuality & 1 & 2 & 3 & 4 \\
\hline 14 & Alcohol & 1 & 2 & 3 & 4 \\
\hline 15 & What you despise about your self & 1 & 2 & 3 & 4 \\
\hline 16 & Your fantasies & 1 & 2 & 3 & 4 \\
\hline 17 & Food & 1 & 2 & 3 & 4 \\
\hline 18 & Who you want to be & 1 & 2 & 3 & 4 \\
\hline 19 & Optimism & 1 & 2 & 3 & 4 \\
\hline
\end{tabular}




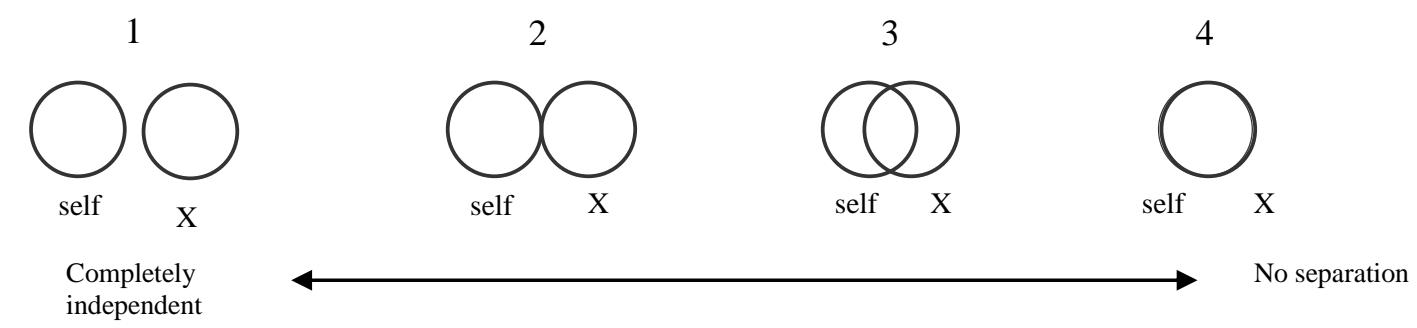

\begin{tabular}{|c|l|llll|}
\hline \multicolumn{7}{|l|}{ Relationship between your self and... } & & & & \\
\hline 20 & Self control & 1 & 2 & 3 & 4 \\
\hline 21 & Prescribed drugs & 1 & 2 & 3 & 4 \\
\hline 22 & Non-prescribed drugs & 1 & 2 & 3 & 4 \\
\hline 23 & T.V. watching & 1 & 2 & 3 & 4 \\
\hline 24 & Your cell phone & 1 & 2 & 3 & 4 \\
\hline 25 & God & 1 & 2 & 3 & 4 \\
\hline 26 & Yourself ten years from now & 1 & 2 & 3 & 4 \\
\hline 27 & Your work & 1 & 2 & 3 & 4 \\
\hline 28 & Your sibling(s) & 1 & 2 & 3 & 4 \\
\hline 29 & Sadness & 1 & 2 & 3 & 4 \\
\hline 30 & Spirituality & 1 & 2 & 3 & 4 \\
\hline 31 & Father & 1 & 2 & 3 & 4 \\
\hline 32 & Yourself five years ago & 1 & 2 & 3 & 4 \\
\hline 33 & Your ethnic group & 1 & 2 & 3 & 4 \\
\hline 34 & Those with power over you & 1 & 2 & 3 & 4 \\
\hline 35 & Those over whom you have power & 1 & 2 & 3 & 4 \\
\hline 36 & Aggressiveness & 1 & 2 & 3 & 4 \\
\hline 37 & Creativity & 1 & 2 & 3 & 4 \\
\hline 38 & Your intelligence & 1 & 2 & 3 & 4 \\
\hline 39 & Happiness & 1 & 2 & 3 & 4 \\
\hline 40 & Hope & 1 & 2 & 3 & 4 \\
\hline 41 & Fate & 1 & 2 & 3 & 4 \\
\hline 42 & Your significant other & 1 & 2 & 3 & 4 \\
\hline 43 & Excitement & 1 & 2 & 3 & 4 \\
\hline 44 & Religion & 1 & 2 & 3 & 4 \\
\hline 45 & Social norms & & & & \\
\hline
\end{tabular}

